\title{
KARL MARX, ANTONIO GRAMSCI E A OMINIDIMENSIONALIDADE: MARXISMO “ATUALIZADO” E A “RACIONALIDADE” DA HISTÓRIA
}

\author{
KARL MARX, ANTONIO GRAMSCI AND OMINIDIMENSIONALITY: “UPDATED” MARXISM AND \\ THE "RATIONALITY” OF HISTORY
}

Antônio Carlos Figueiredo Costa*

\begin{abstract}
RESUMO
A intenção do presente trabalho é assinalar a expressiva contribuição do intelectual italiano Antonio Gramsci (1891-1937) para a teoria marxista, evidenciando com isso a permanente construção teórica, filosófica e metodológica peculiar ao marxismo. Gramsci ocupa na história da evolução do marxismo um momento axialmente transformador, por haver rompido com o economicismo, o positivismo e o evolucionismo da II Internacional (1889-1915), tendo se beneficiado do historicismo crociano o qual, mediante exercício dialético, logrou reformular e, com isso, possibilitar a valorização de aspectos superestruturais na mudança revolucionária da sociedade, elevando a cultura e a educação a fatores condicionantes decisivos na formação política da classe trabalhadora, e ensejando a realização da ominidimensionalidade humana, conforme preconizada por Karl Marx (1818-1883), sobretudo em seus escritos de juventude.
\end{abstract}

PALAVRAS-CHAVE: Marxismo. Karl Marx. Antonio Gramsci. Educação. Cultura.

\section{ABSTRACT}

The intention of this work is to point out the expressive contribution of the Italian intellectual Antonio Gramsci (1891-1937) to the Marxist theory, thus evidencing the permanent theoretical, philosophical and methodological construction peculiar to Marxism. Gramsci occupies in the history of the evolution of Marxism an axially transforming moment, having broken with the economism, positivism and evolutionism of the Second International (18891915), having benefited from the Crocean historicism which, through dialectical exercise, managed to reformulate and (1818-1883), and thus to make possible the valorization of superstructural aspects in the revolutionary change of society, raising culture and education to decisive determining factors in the political formation of the working class and bringing about the realization of human omnidimensionality, as advocated by Karl Marx (1818-1883) , especially in his youth writings.

KEY-WORDS: Marxism. Karl Marx. Antonio Gramsci. Education. Culture.

\footnotetext{
Doutor em História. Professor de História na Universidade do Estado de Minas Gerais. E-mail: antoniocarlosfigueiredohist@gmail.com.
} 


\section{INTRODUÇÃO}

Nascido na pequena Ales, interior da Sardenha, Antonio Gramsci representa na história do marxismo uma síntese de virtudes alinhadas à ideia de superação. Pobre, fisicamente defeituoso e portador de uma formação acadêmica irregular - mas nem por isso tão precária como era a sua saúde - teve como um dos principais méritos ampliar o escopo das restritas análises marxistas que à sua época pululavam, densificando-as, e com isso, retirando-as do restrito economicismo, derrubando por terra o voluntarismo, expurgando os resquícios do positivismo da II Internacional e, por fim, reabrindo em termos teóricometodológicos o cabedal de possibilidades para a construção de uma forma revolucionária de sociedade na qual se tornasse possível o parto de um novo tipo de homem, mais solidário, ético, e portador de uma forma de cultura que fosse capaz de revelar-se em ato vital, capaz de apresentar-se não sob um agregado de saberes divorciados da realidade, mas criação histórica e, portanto, humana.

Conforme é sabido, Karl Marx havia apresentado em escritos de juventude, mais especificamente nos Manuscritos econômicos e filosóficos, mas também um pouco mais tarde, na Introdução à contribuição à crítica da economia política, argumentos em favor de uma ação emancipadora do homem, denominada por práxis e tornada um dos conceitos centrais do marxismo. Mas a crítica da cultura burguesa, para que fosse realizada com eficácia, necessitava de um amplo domínio do material ideológico mais avançado dessa cultura. $\mathrm{O}$ conceito de práxis refere-se em geral a uma ação, a uma atividade. Práxis é palavra de origem grega. No sentido que lhe atribuiu Marx, a práxis representa a atividade livre, universal, criativa e edificante, por meio da qual o homem cria, ou seja, faz e produz, transforma e, com isso, dá conformação ao mundo que é humano e histórico, bem como a si mesmo. A práxis se constitui portanto em uma atividade que é específica do ser humano, e que praticamente torna o homem radicalmente diferente de todos os outros seres. Dessa forma, o homem pode ser considerado o ser da práxis.

Contudo, conforme constatara Marx, as forças do capital haviam tornado o trabalho em aprisionamento do ser humano, encarcerando a sua plenitude criativa, enfim, o sistema capitalista havia coisificado tanto o trabalho humano, quanto o próprio homem e, com isso, retirado a possibilidade do desenvolvimento pleno do seu caráter, da sua personalidade. Com efeito, nas relações de produção impostas pelo capitalismo, o homo sapiens fora tornado progressivamente em homo faber, ser unidimensional e condenado doravante a servir como 
Artigo: Karl Marx, Antonio Gramsci e a ominidimensionalidade: o marxismo "atualizado" e a

"racionalidade" da história

anexo de carne a uma máquina. Da peça acusatória marxista constava que nesse sistema de produção o homem com seu trabalho, principal elemento das forças produtivas, que constituem conforme é sabido, as condições materiais de toda a produção, apesar de ser o principal elemento dessas forças, pois responsável por fazer a ligação entre a natureza, a técnica e os instrumentos, fora alienado sistematicamente da posse desses meios de produção e, consequentemente, do produto final dessa produção.

É comumente aceito que um dos saltos qualitativos na obra de Marx, em termos de proposição de mudanças na sociedade, fica representado por pavimentar o hiato antes existente entre uma discussão que se fazia no âmbito dos socialistas utópicos - no que tratou de reconhecendo-lhes seu valor e pioneirismo - Saint-Simon, François-Charles Fourier, Robert Owen - para lançar pontes à dialética hegeliana e à sua apologia ao Estado Moderno, que tratou de denunciar veementemente, mas também de uma fundamentada crítica aos economistas clássicos, como Adam Smith e David Ricardo, os quais combateu em seus próprios termos e território epistemológico. Dessa forma, nesse diálogo criativo e criador, e mediante a formulação dos princípios básicos de uma teoria libertadora expressa em métodos de análise que ficaram conhecidos por materialismo histórico, passou a ficar mais nítida a relação que se estabeleceu ao longo dos tempos entre as forças produtivas e as relações de produção. A História humana havia sido até então, segundo Marx, um embate contínuo entre dominantes e dominados. E modelos de família, de religião, das leis e das ideias políticas plasmariam na realidade a visão desses grupos dominantes. Era preciso portanto libertar a humanidade da exploração material, e de tantas outras opressões, de natureza simbólica. A partir de Marx, tudo seria histórico, portanto transitório e não absoluto, ou seja, passível de ser mudado. Marx começara a realizar, mediante a construção de sua imensa obra teórica, uma verdadeira revolução copernicana, de caráter irreversível a interpelar toda a humanidade acerca dos rumos a trilhar, denunciando a existência de uma encruzilhada cujo horizonte de expectativas apontava para a drástica escolha entre o socialismo e a barbárie.

Cabe ressaltar no entanto que, à época da juventude de Marx, as lutas do proletariado deveriam visar prioritariamente o estabelecimento de uma plataforma de ideias que fosse coerente em sua análise de conjuntura e que, concomitantemente a isso, lograsse reunir os trabalhadores sob um pensamento logicamente formulado e racionalmente conduzido, condição que autoriza a tratar o marxismo tanto como uma ciência em construção, quanto como uma estratégia de lutas das mais satisfatórias. Ora, face à sofisticada elaboração teórica com a qual pôde contar o marxismo logo em seus primeiros momentos, e devido às severas 
limitações de acesso à cultura formal enfrentadas pelos trabalhadores à época de Karl Marx e Friedrich Engels, não foi por mero acaso que os principais fautores dessas ideias tenham sido esses dois intelectuais de origem burguesa. No início do século XX, Antonio Gramsci iria envidar esforços no sentido de interrogar acerca dos motivos da crise na qual ficara envolvido o marxismo, recolocando a questão da cultura como fator decisivo na luta contra o capital e, com isso, propondo o deslocamento do epicentro das ações do campo da infraestrutura para os aspectos superestruturais da sociedade.

\section{MARX E A OMINIDIMENSIONALIDADE}

Conforme anteriormente adiantamos, o marxismo havia sido elaborado como uma crítica à sociedade burguesa, a partir de uma interpelação científica à economia política inglesa, ao socialismo francês e à filosofia clássica alemã. Essa crítica da sociedade burguesa apareceu em notável amplitude nos Manuscritos econômico-filosóficos (2010), escritos em 1844. Marx realizara ao longo dessa pequena obra uma apreciação de caráter ético que descortinava a subversão dos valores vinculados ao trabalho, quando submetidos aos pressupostos estruturais da sua subordinação aos interesses do capital. Marx apoiara-se então em crenças que envolviam não somente a realização humana decorrente do trabalho, mas também naquilo que poderíamos chamar como a própria salvaguarda dos valores morais e éticos que deveriam cimentar a continuidade da trajetória humana, os quais se viam em risco, face ao estancamento da humanidade inerente ao trabalhador, pelos processos desumanizadores experimentados e decorrentes nas relações de trabalho. O trabalhador se via então reduzido à situação de homo faber, subvertendo assim sua relação com a atividade laboriosa que havia afinal, elevado os seres humanos, desde priscas eras, à condição de homo sapiens. O estranhamento causado pelas determinações do sistema de propriedade privada, com a apropriação de parte do trabalho pelo capital, aparece então como objeção socioeconômica à realização humana, levando à negatividade do trabalho que passaria a produzir não mais realização e promoção do ser humano, mas desigualdades sociais cada vez maiores, replicadas não somente nas condições materiais de existência, mas transmitidas também, conforme propõe o conceito marxista de alienação, nas manifestações do espírito humano, como as atividades próprias à cultura.

Porém, conforme nos lembra Leandro Konder (1965, p. 154-155), tais parâmetros de libertação teriam que esperar outro momento, pois, 
[...] o marxismo tinha de procurar mobilizar rapidamente as massas, atuando didaticamente sobre elas. Como as massas haviam sido relegadas pela exploração classista a níveis baixíssimos de cultura e se achavam embrutecidas por preconceitos multisseculares, a tarefa didática levou o marxismo a se simplificar e a se combinar com formas culturais pouco superiores à cultura popular de nível médio, que era medieval.

Cabe esclarecer que Marx e Engels não haviam empreendido qualquer forma de estudo que pudesse ser considerada sistemática ou suficiente a tornar-se uma espécie de manual que encorajasse a melhoria da cultura do proletariado. No entanto, na opinião de Adolfo Sánchez Vázquez, devemos considerar que mesmo nas obras lavradas sob caráter filosófico ou econômico, tais como os Manuscritos econômico-filosóficos de 1844, e os estudos para uma crítica da economia política, ou ainda, para relacionarmos uma obra da maturidade que é $O$ capital, podemos encontrar:

[...] ideias de Marx que possuem uma relação direta com problemas estéticos e artísticos fundamentais: a arte e o trabalho, a essência do estético, a natureza social dos sentidos estéticos, a arte como forma de superestrutura ideológica, o condicionamento de classe e relativa autonomia da obra artística, o desenvolvimento desigual da arte e da sociedade, as relações entre a arte e a realidade, a ideologia e o conhecimento, a criação artística e a produção material sob o capitalismo, a arte e a realidade, a perdurabilidade da obra artística, etc. (VÁZQUEZ, 1968, p. 10).

Cumpre no entanto assinalar que as observações que trataram de forma um tanto quanto dispersa sobre a arte ou a literatura acabaram por ser abandonadas àquilo que Marx chamara de crítica roedora dos ratos. Afinal, para ele, a lavra dos Manuscritos econômicofilosóficos ou da Contribuição à crítica da economia política havia cumprido o singelo papel de organização das ideias para obras futuras e na sua opinião, de caráter mais definitivo, destinadas portanto a plasmar, de maneira irretocavelmente decisiva, seu veredicto de condenação às relações vigentes na sociedade, sob o capitalismo.

Leandro Konder (1967) reforçou a ideia de que, como toda concepção de mundo, o marxismo havia constituído a sua própria teoria estética, que passou a ficar integrada à sua teoria do conhecimento. Assim, cabe ressaltar com esse autor que parte significativa de uma grande massa documental que compõe o corpus teórico marxista e na qual ineludivelmente ficam inclusas a Introdução à contribuição à crítica da economia política, os Manuscritos econômico-filosóficos, bem como a cartas trocadas entre Marx e Engels, textos que somente vieram a lume, recebendo com isso uma real difusão, apenas no século XX, quando surgiram estampadas por Karl Káutski ainda nos primeiros anos daquele século, ou mesmo já na década dos anos de 1930, quando Georg Lukács em trabalho conjunto com o historiador e crítico 
soviético Mikhail Lifschitz, coligiu todos os escritos nos quais Marx e Engels afloraram os problemas da cultura, ao abordar temas como a arte e a literatura.

Com esses esclarecimentos em mente, cumpre perceber que mesmo à época de Marx já havia uma produção teórica formadora do que poderíamos chamar por estética marxista, à qual agrupava algumas formulações que teorizavam acerca da divisão de trabalho imposta aos homens na sociedade de classes sob o sistema capitalista, ou seja, que nos permitem pensar que atividades a envolver o intelecto e a criatividade não deveriam ser apanágio de indivíduos considerados excepcionais, o que valeria dizer, a alguns especialistas escolhidos por seus talentos que passam a desligar-se da massa do povo. Pois uma sociedade que visasse a um futuro sob o socialismo não poderia permitir as amarras que pretendiam fazer do homem um ser unidimensional, sob uma esfera exclusiva de atividades, mas alguém que venha a se tornar completo no ramo no qual desejar, ou como escreveu Tom Bottomore (1988, p.18), fazendo "uma coisa num dia e outra coisa amanhã, caçar pela manhã, pescar à tarde, cuidar do gado ao entardecer e dedicar-se à crítica depois do jantar, sem que, por isso, o indivíduo deva tornar-se caçador, pescador, pastor ou crítico".

\section{GRAMSCI EM DIÁLOGO COM O JOVEM MARX}

O curto prazo dado pela urgência de politização das massas fez com que o marxismo se tornasse popularesco e vulgarizado, levando a crer que se encontrava em crise, conforme supunham, no apagar das luzes do século XIX, teóricos como Eduard Bernstein, na Alemanha, Georges Sorel, na França, ou Benedetto Croce, na Itália (GERRATAMA, 1984, p. 46). A crítica apontava, conforme explicou Carlos Nélson Coutinho (1981, p. 19), para a concepção positivista-evolucionista que se instaurara entre os dirigentes socialistas da II Internacional. O Partido Socialista Italiano (PSI) foi fundado tardiamente em 1892, e a essa época, destacava-se no cenário intelectual Antonio Labriola, professor de filosofia moral e pedagogia na Universidade de Roma, que seria futuramente considerado o líder espiritual do socialismo italiano. Labriola realizara uma demorada migração das posições políticas mais moderadas para o radicalismo socialista, no qual se considerava finalmente ambientado por volta de 1879 (GERRATAMA, 1984, p. 23). Labriola manteve uma experiência concreta com a luta do proletariado italiano e pôde rever concepções teóricas, tanto através da leitura direta dos textos de Karl Marx e Friedrich Engels - comprados no mercado internacional - quanto pela copiosa relação epistolar mantida com Engels, o qual, aliás, intermediou para que muitos 
Artigo: Karl Marx, Antonio Gramsci e a ominidimensionalidade: o marxismo "atualizado" e a

"racionalidade" da história

livros antigos e raros chegassem às suas mãos. Segundo Carlos Nelson Coutinho (1981, p. 19), à época de Labriola, a concepção positivista-evolucionista dos dirigentes da II Internacional:

\begin{abstract}
[...] servia como uma luva para justificar ideologicamente a prática política imobilista, fatalista, que predominava então nas correntes em que se dividia a maioria do PSI. Tal como Kautsky, o grande maître à penser da II Internacional, os principais ideólogos do PSI entendiam a revolução proletária como o resultado de uma inexorável lei do desenvolvimento econômico: o progresso das forças produtivas, aguçando a polarização de classe e conduzindo a crises de tipo catastrófico, levaria fatalmente, em dado momento, a um colapso do capitalismo, com a conseqüente irrupção da insurreição proletária. Enquanto isso, cabia ao proletariado fortalecer ao máximo suas organizações e esperar pelo 'grande dia'; à intransigência doutrinária, juntava-se uma posição objetivamente passiva, de expectativa imobilista. $\mathrm{O}$ marxismo era interpretado como uma defesa dos fatos contra a vontade, da objetividade 'natural' contra a subjetividade criadora.
\end{abstract}

Conforme explicou Coutinho (1981), a influência de Labriola sobre Antonio Gramsci não foi decisiva, pelo menos na sua juventude. Mas cabe considerar certa ascendência ainda que indireta do líder espiritual do socialismo italiano, por intermédio dos textos de Benedetto Croce, autor a quem Gramsci (1978, p. 208) considerou no início dos anos de 1930 como sendo o “...líder intelectual das tendências revisionistas dos anos 90". Croce havia rompido com seu antigo mestre, Labriola, ao escrever uma série de ensaios, publicados em 1900, nos quais dialogava criticamente com a teoria marxista e com o 'pai' do marxismo italiano, dedicando a obra a este último, com as seguintes palavras "à memória de Antonio Labriola que me iniciou nestes estudos" (CROCE, 1948, p. 7). Croce temia então que o marxismo convergisse decisivamente, cumprindo certo papel histórico que alguns consideravam histórico, de formalizar em um campo teórico e prático a força política do proletariado. Para ele, a materialização dessa força política se daria no impulso vertiginoso das massas populares em direção à tomada do poder; seria um abalo social somente comparável às jacqueries ocorridas na França do século XIV, ou às guerras camponesas alemãs, ocorridas na centúria seguinte. Principal intérprete intelectual do liberalismo democrático na Itália de finais do dezenove e primeira metade do século vinte, Croce influenciaria Antonio Gramsci, estudante de Letras na Universidade de Turim. Entre os meses finais de 1914 e começos de 1915, Gramsci assistira a um curso sobre o marxismo ministrado pelo professor Annibale Pastore, um intelectual não marxista. Do programa constavam leituras de Benedetto Croce que ofereceram ao jovem estudante uma visão sistemática da obra de Marx, bem como o resgate crociano do historicismo. 
Pelo estudo de Croce, ficava permitido a Gramsci criticar "a determinação geral do avanço da história pelas condições materiais de existência” (MAESTRI; CANDREVA, 2007, p. 49) ficando possível também a partir disso, a proposição do desenvolvimento do espírito humano. Assim, conforme escreveu Leandro Konder (1967), na sua maturidade intelectual, ou seja, o Gramsci dos Cadernos do cárcere, se tornaria realizável combater as deformações do marxismo, fosse pela tendência que se autointitulara ortodoxa, fundada sob um materialismo que se revelava vulgar, de fatalismo mecanicista e positivista, fosse pela concepção idealista esposada por Benedetto Croce. Para Leandro Konder (1967, p. 112-113), um dos grandes méritos de Antonio Gramsci teria sido a capacidade de incorporar "à sua própria elaboração, ainda que como momento subordinado, as exigências porventura válidas contidas no ponto de vista do adversário", o que o levou a entender que para a adequada percepção acerca dos grandes conflitos humanos teria que se prestar maior importância ao caráter ativo das superestruturas, o que lhe caberia a tarefa complementar de prestar uma singela homenagem a Benedetto Croce, seu contendor ideológico, pela atenção que despertara acerca da cultura e do pensamento no desenvolvimento da História.

A tarefa apresentava-se na sua imensidão, e os embates deveriam ocorrer no espaço em uma tarefa de enfrentamento entre o proletariado e a burguesia. Um duelo diuturno no qual os trabalhadores deveriam aprender a combater com as armas do adversário, ou seja, a cultura, em uma luta pela hegemonia da classe na sociedade, marcada para ocorrer mesmo antes da tomada definitiva do poder político. Essa foi a tarefa político-pedagógica na qual se destacou Antonio Gramsci, ao demonstrar o papel exercido pela sociedade civil, que juntamente à chamada sociedade política - entendida tradicionalmente como o espaço de determinação do poder - se constitui em espécie de Estado Ampliado (sociedade política somada à sociedade civil), menos suscetível e vulnerável portanto a qualquer tomada intempestiva do poder pela força.

Assim, cabe frisar, o lugar de aplicação do conceito de hegemonia seria a sociedade civil, e as armas de luta do proletariado, a cultura. Daí o papel a ser exercido pelos intelectuais orgânicos dessa classe laboriosa que, para Gramsci, deveria tornar-se dirigente antes mesmo de chegar ao poder, no que lhe compete o domínio dos aparelhos ideológicos e culturais da hegemonia, entre eles, a Escola. De acordo com Luna Galano Mochcovitch (1990), a reavaliação proposta por Gramsci para o conceito de sociedade civil primou pelo afastamento do sistema de relações econômicas sobre os quais Marx centrara seu esforço de análise, para dirigir-se às instituições que regulamentariam tanto essas relações, quanto as sociais e a vida 
Artigo: Karl Marx, Antonio Gramsci e a ominidimensionalidade: o marxismo "atualizado" e a

"racionalidade" da história

cultural em geral . Haveria então, um "deslocamento" da sociedade civil, do campo da estrutura para o da superestrutura (Bobbio apud Mochcovitch, 1990, p. 29), reavaliação que segundo essa autora, não seria o que liga Gramsci a Marx, mas precisamente o que o separa dele. Nesse aspecto, Gramsci priorizou os aspectos da política, na sua obra de maturidade, os Cadernos do cárcere, escritos em precárias condições entre o início de 1929 até abril de 1935, na prisão de Turi, província de Bari, onde cumpria pena determinada por um tribunal fascista (GRAMSCI, 1999, p. 9). Conforme observou Coutinho (1989), o ponto focal de Antonio Gramsci, ou seja, o núcleo do seu pensamento, está localizado na política. Caberá, antes de passar ao exame de alguns dos principais conceitos mobilizados por Gramsci, compreender, pela lavra de Carlos Nelson Coutinho, reputado como um dos mais autorizados comentaristas brasileiros da obra de Gramsci, o que o autor dos Cadernos do cárcere pretendia significar com o conceito de política. Assim, para Coutinho (1999, p. 52-53):

\begin{abstract}
Gramsci usa esse conceito em dois sentidos, que poderíamos chamar de 'amplo' e de 'restrito'. Em sua acepção ampla, o político identifica-se praticamente com liberdade, com universalidade, com toda forma de práxis que supera a mera recepção passiva ou a manipulação de dados imediatos (passividade e manipulação que caracterizam boa parte da práxis técnico-econômica e da práxis cotidiana em geral) e se orienta conscientemente para a totalidade das relações subjetivas e objetivas.
\end{abstract}

Após ser identificada a política como núcleo central entre os temas tratados por Antonio Gramsci, cumpre esclarecer alguns conceitos que transitam por sua obra, cuja compreensão nos parece, nesse momento como imprescindíveis a que pensemos o papel da cultura como requisito indispensável à conquista da ominidimensionalidade do homem. Esses conceitos gravitam pelo universo da política gramsciana, ou seja, a política considerada em sentido lato, e mantém relação com as lutas do proletariado para sobrepor as razões da liberdade à necessidade. Assim, consideramos neste momento como imprescindíveis de algumas considerações os conceitos de hegemonia, bloco histórico, intelectual orgânico e revolução passiva, conforme entendidas por alguns estudiosos dedicados à obra de Antonio Gramsci. Para Anne Showstack Sassoon (1993, p. 177), devemos o pleno desenvolvimento do conceito marxista de hegemonia a Gramsci, que nos Quaderni del carcere passa a aplicá-lo ao modo pelo qual a burguesia estabelece e mantém a sua dominação. Acresce ainda esta autora que a tessitura da hegemonia gramsciana é realizada pelos intelectuais, que para Gramsci seriam todos aqueles que têm um papel organizativo na sociedade. De acordo com Luciano Gruppi (1980, p. 80), o conceito gramsciano de hegemonia também pode ser entendido como 
"uma chave de leitura histórica, de análise de processos". Para esse autor, uma classe seria hegemônica, dirigente e dominante mediante a sua ação política, ideológica e cultural em manter articulados grupos de forças heterogêneas, impedindo assim a explosão de contrastes entre estes grupos, o que provocaria crise na ideologia dominante.

Luciano Gruppi (1980, p. 78) observa também que Gramsci deixou sublinhado que a hegemonia conteria uma relação pedagógica, sendo esta "uma relação nova entre teoria e práxis porque é uma relação nova entre cultura e massas, entre intelectuais e massas". Ainda de acordo com Gruppi (p. 68), a forma pela qual a ideologia da classe dominante chegaria às classes subalternas seria por canais, sendo os mais conhecidos a Escola - com a sua fratura de classe entre futuros quadros dirigentes e ocupantes de posições subalternas, a Igreja - com sua capacidade através do catecismo - de imprimir precocemente nas massas determinada concepção de mundo - os jornais locais - com seus pequenos episódios de cultura local -, além do serviço militar.

Christinne Buci-Glucksmann, que na qualidade de comentarista dos escritos gramscianos também aparece com notado relevo, observou que o conceito de hegemonia passa a ser designado com a maturidade do pensamento de Gramsci pelo novo conceito de aparelho de hegemonia, utilizado sobretudo para as práticas da classe dominante. Para essa autora, os conceitos de hegemonia e de aparelhos de hegemonia "não são diretamente vinculados à problemática do Estado, e sim à da constituição de classe, em um processo de transformação revolucionária" (BUCI-GLUCKSMANN, 1980, p. 70). Marcado pela primazia da luta de classes, na visão da autora, o aparelho de hegemonia qualifica e precisa a hegemonia, entendida como hegemonia política e cultural das classes dominantes. Pari passu à noção de hegemonia, caminharia a ideia de supremacia, sendo esta domínio e direção, a hegemonia avançando com a afirmação da capacidade de direção política.

Cabe ressaltar ainda, que para Luciano Gruppi (1990), a hegemonia tenderia a construir um bloco histórico. Segundo Hugues Portelli, para que possamos apreender a noção de bloco histórico, o aspecto essencial da tarefa deve consistir na percepção da relação entre estrutura e superestrutura, sem conceber-se - segundo assinalado pelo autor - qualquer primazia entre um ou outro elemento. A relação estruturas-superestruturas possui por ponto essencial o estudo do vínculo que realiza sua unidade, sendo este vínculo qualificado por Gramsci como orgânico, sendo realizado por certos grupos sociais cuja função é operar não ao nível econômico, mas superestrutural. Esses grupos seriam formados pelos intelectuais. 
Artigo: Karl Marx, Antonio Gramsci e a ominidimensionalidade: o marxismo "atualizado" e a "racionalidade" da história

Recorrendo novamente a Anne Showstack Sassoon (1993), poderíamos tornar mais explícita a noção de bloco histórico como a forma pela qual uma classe manteria seu domínio, não simplesmente pela organização específica da força, "mas por ser capaz de ir além de seus interesses corporativos estreitos, exercendo uma liderança moral e intelectual e fazendo concessões dentro de certos limites, a uma variedade de aliados unificados num bloco social de forças"(1993, p. 177), desde que compreendamos, como defende Portelli (1990, p.16), que o bloco histórico não é uma simples aliança entre classes sociais, mas sim "ponto de partida de uma análise: a análise da maneira como um sistema de valores culturais (o que Gramsci chama de ideologia ) impregna, penetra, socializa e integra um sistema social”.

Caberia ainda atribuir sentido ao intelectual orgânico de Gramsci. Sabemos conforme assinalado anteriormente, que intelectuais seriam todos aqueles que têm papel organizativo na sociedade, cabendo a esses realizar a tessitura da hegemonia gramsciana. Sabemos também que a tais intelectuais cabe a tarefa de realizar o vínculo - qualificado por Gramsci de vínculo orgânico - na relação estrutura-superestrutura. Com efeito, à medida que se desenvolveram as funções econômicas e sociais burguesas, tornou-se necessário confiar a grupos especializados - compostos por burgueses ou indivíduos de classes aliadas à burguesia - a gestão das funções organizativas da superestrutura ideológica, jurídica e política (PORTELLI, 1990, p. $15)$.

Nesse sentido, caberia realçar a capacidade de agenciamento que deve possuir o intelectual orgânico da classe trabalhadora, face à tarefa que assume na sociedade civil gramsciana. Em uma perspectiva de Estado Ampliado, encontra-se colocada a esse intelectual a tarefa fundamental de contribuir para a garantia da elevação cultural das massas, que inclui não apenas a escola, mas também aos chamados serviços públicos intelectuais, os quais, segundo Portelli (1990, p. 35), devem englobar instituições como teatros, bibliotecas, museus e jardins zoológicos, serviços esses que não devem ser abandonados à iniciativa privada. Cabe ainda registrar que a cultura para Gramsci, conforme esclareceu Marco Antonio Villela Pamplona (1983, p. 18-19), não se constitui em noção a ser confundida com saberes enciclopédicos, pedanterias ou informações soltas ou desconexas da realidade. Assim, a questão acerca da democratização da cultura, ocupa na agenda gramsciana um fator sine qua non à conquista da ominidimensionalidade humana. 


\section{CONSIDERAÇÕES FINAIS}

O texto procurou apresentar o intelectual marxista Antonio Gramsci como um investigador perspicaz e crítico, atuando no calor dos acontecimentos e forçado a tomar decisões quase sempre em meio a um crisol de lutas. Seus escritos de maturidade foram lavrados no interior de prisões do regime fascista. Mas, apesar de tudo isso, ou talvez até mesmo para superar situações tão desesperadoras, Antonio Gramsci foi capaz de corajosamente abandonar os excessos teleológicos que o aprendizado do marxismo realizado no bojo da II Internacional propunha, para acatar as lições da História, em que ficava demonstrado que o conhecimento científico e filosófico progride através das polêmicas, como as que foram suscitadas através das lições do historicismo de Benedetto Croce. Gramsci conseguiu reavaliar a sociedade civil, ao deslocá-la da posição de infra-estrutura, conforme havia feito Marx, para a superestrutura, enriquecendo com isso a teoria do Estado junto ao pensamento marxista, e revalorizando o conceito de práxis.

Na visão gramsciana de um mundo em transformação, que marcharia a largos passos para o socialismo, a cultura teria que estar inserida na realidade histórica à qual se integra. A cultura seria parte de um processo de expansão da hegemonia, e o proletariado possuía necessidade de manifestações culturais próprias e diversas da cultura burguesa dominante. Assim, a cultura passava a ser parte constitutiva da consciência do proletariado acerca do processo histórico, inscrevendo-se consequentemente no próprio conceito de práxis conforme o entendeu Antonio Gramsci, ou seja, como o fazer-se da História, ou a realização da História, por força da vontade racional, vontade esta que seria suscitada por um pensamento historicamente baseado.

\section{REFERÊNCIAS}

BOGO, Ademar (org.). Teoria da organização política II. 2.ed. São Paulo: Expressão Popular, 2010.

BOTTOMORE, Tom. Verbete Arte. In: BOTTOMORE, Tom (org.). Dicionário do Pensamento Marxista. Rio de Janeiro: Zahar, 1988, p.17-20.

BUCI-GLUCKSMANN, Christinne. Gramsci e o Estado. Rio de Janeiro: Paz e Terra, 1980.

CACCIATORE, Giuseppe. Verbete historicismo. In: LIGUORI, Guido; VOZA, Pasquale (orgs.). Dicionário Gramsciano: 1926 - 1937. São Paulo: Boitempo, 2017. 
Artigo: Karl Marx, Antonio Gramsci e a ominidimensionalidade: o marxismo "atualizado" e a

"racionalidade" da história

COUTINHO, Carlos Nelson. Gramsci. Porto Alegre: L\&PM, 1981.

COUTINHO, Carlos Nelson. Gramsci: um estudo sobre seu pensamento político. Rio de Janeiro: Campus, 1989.

CROCE, Benedetto. Materialismo histórico e economia marxista. São Paulo: Progresso Editorial, 1948.

DIAS, Edmundo Fernandes. Cultura, política e cidadania na produção gramsciana de 1914 a 1918. Cadernos do CEDES. V.3: Educação e política: Gramsci e o problema da hegemonia. Campinas, 1983, p. 31-56.

GERRATAMA, Valentino. Antonio Labriola e a introdução do marxismo na Itália. In: HOBSBAWM, Eric J. História do Marxismo: IV (o marxismo na época da segunda internacional). Rio de Janeiro: Paz e Terra, 1984.

GRAMSCI, Antonio. Cadernos do cárcere. V.1. Introdução ao estudo da filosofia. A filosofia de Benedetto Croce. Rio de Janeiro: Civilização Brasileira, 1999.

GRAMSCI, Antonio. Cadernos do cárcere. V.3. Maquiavel. Notas sobre o Estado e a política. 2.ed. Rio de Janeiro: Civilização Brasileira, 2002.

GRAMSCI, Antonio. Cadernos do cárcere. V.4. Temas de cultura. Ação católica. Americanismo e fordismo. 3.ed.Rio de Janeiro: Civilização Brasileira, 2011.

GRAMSCI, Antonio. Concepção dialética da História. 2. ed. Rio de Janeiro: Civilização Brasileira, 1978.

GRUPPI, Luciano. O conceito de hegemonia em Gramsci. 2. ed. Rio de Janeiro: Graal, 1980.

KONDER, Leandro. Marxismo e alienação: contribuição para um estudo do conceito marxista de alienação. Rio de Janeiro: Civilização Brasileira, 1965.

KONDER, Leandro. Os marxistas e a arte: breve estudo histórico-crítico de algumas tendências da estética marxista. Rio de Janeiro: Civilização Brasileira, 1967.

MAESTRI, Mário; CANDREVA, Luigi. Antonio Gramsci: vida e obra de um comunista revolucionário. 2.ed. São Paulo: Expressão Popular, 2007.

MARX, Karl. Contribuição à crítica da economia política. 2.ed. São Paulo: Expressão Popular, 2008.

MARX, Karl. Manuscritos econômico-filosóficos. São Paulo: Boitempo, 2010.

MOCHCOVITCH, Luna Galano. Gramsci e a Escola. 2.ed. São Paulo: Ática, 1990. 
PAMPLONA, Marco Antonio Villela. A questão escolar e a hegemonia como relação pedagógica. Cadernos do CEDES. V.3: Educação e política: Gramsci e o problema da hegemonia. Campinas, 1983, p. 2-30.

PORTELLI, Hugues. Gramsci e o bloco histórico. 5. ed. Rio de Janeiro: Paz e Terra, 1990.

SASSOON, Anne Showstack. Hegemonia. In: BOTTOMORE, Tom, org. Dicionário do pensamento marxista. Rio de Janeiro: Zahar, 1993.

VÁZQUEZ, Adolfo Sánchez. As ideias estéticas de Marx. Rio de Janeiro: Paz e Terra, 1968. 